\title{
The Effects of Body Mass Index on Softball Pitchers' Hip and Shoulder Range of Motion
}

\section{(우(1) $(9)$}

\author{
Authors \\ Kenzie B. Friesen ${ }^{1}$, Adam W. Anz ${ }^{2}$, Jeffrey R. Dugas ${ }^{3}$, James R. Andrews ${ }^{2}$, Gretchen D. Oliver ${ }^{1}$
}

\section{Affiliations}

1 School of Kinesiology, Auburn University, Auburn, AL, USA

2 Andrews Research and Education Foundation, Gulf Breeze, FL, USA

3 Andrews Sports Medicine and Orthopaaedic Center, Birmingham, AL, USA

\section{Key words}

Fast-pitch softball, functional measures, injury, obesity, windmill softball pitch

received $\quad 07.07 .2020$

revised 11.08 .2020

accepted after revision $\quad 12.08 .2020$

Bibliography

Sports Medicine International Open 2020; 4: E8-E13

DOI 10.1055/a-1244-1621

ISSN 2367-1890

(c) 2020. The Author(s).

This is an open access article published by Thieme under the terms of the Creative Commons Attribution-NonDerivative-NonCommercial-License, permitting copying and reproduction so long as the original work is given appropriate credit. Contents may not be used for commecial purposes, or adapted, remixed, transformed or built upon. (https://creativecommons.org/ licenses/by-nc-nd/4.0/)

\section{Correspondence}

Dr. Gretchen D. Oliver

School of Kinesiology, Auburn University

301 Wire Rd

36849 Auburn

United States

Tel.: +1 8592004035

www.sportsmedicineandmovementau.com

goliver@auburn.edu

\section{ABSTRACT}

Currently it is hypothesized that increased body mass index may contribute to overuse injuries. Thus, if hip or shoulder range of motion is affected by body mass index, pitchers may be placing additional stress on joints as they seek to pitch at maximal velocity. The purpose of this study was to examine if range of motion at the hips and shoulders were related to body mass index classification. A sample of 147 female softball pitchers $(17.0 \pm 4.2$ years; $167.6 \pm 11.8 \mathrm{~cm} ; 70.6 \pm 17.5 \mathrm{~kg}$; body mass index $=24.8 \pm 4.7 \mathrm{~kg} / \mathrm{m}^{2}$ ) participated. Bilateral hip and shoulder range of motion were assessed. Multivariate analysis of variance results indicated body mass index [Wilks' $\Lambda=0.742$, $\left.F=1.722, p=0.014, \eta^{2}=0.095\right]$ significantly affected range of motion of the shoulder and hip. Post hoc results indicated the underweight group had significantly more range of motion than the obese group in hip internal range of motion on both the throwing side (mean difference $=12.39, \mathrm{p}=0.005$ ) and glove side (mean difference $=11.98, p=0.004$ ). Although body composition is not overly emphasized among softball pitchers, the current study reveals excess weight may inhibit proper mechanics. Coaches, athletic trainers, strength and conditioning personnel, and athletes should acknowledge the role that body composition can play in affecting pitch outcomes.

\section{Introduction}

Obesity is a persistent problem in America, as reports show that from 1999-2000 through 2015-2016, there was a significant increase in obesity among youth and adults [1]. The increasing prevalence of obesity, while problematic for numerous health reasons, also gives rise to an increased risk of sports injury among athletes $[2,3]$. Research has shown that adolescents who were of a healthy weight had lower rates of injury than those who were in a higher range of body mass index (BMI) [4]. Higher BMI has been suggest- 
ed to be a risk factor specifically in overuse injuries, due to the higher relative strain on the musculoskeletal system during repetitious tasks [5].

Softball pitching is a highly repetitive and strenuous movement that involves sequential kinetic chain usage [6]. The whole body is required to sequentially transfer energy from the lower extremity to the upper extremity, therefore appropriate strength and ROM of both the hips and shoulders is essential [7]. Research has shown that in lieu of the repetitious nature of pitching, both hip and shoulder ROM adaptations occur over time according to both age and player position [8]. These musculoskeletal adaptations that occur over the course of an athlete's career imply functional changes may be a result of high repetition. As career repetitions increase, these demanding sport positions and repetitious tasks promote physical adaptations in the hip and shoulder [9-13]. Some musculoskeletal adaptations may be advantageous to a point, such as increased throwing shoulder external rotation (ER) to allow for maximal acceleration of the ball $[14,15]$. Contrarily, other research has noted certain adaptations to be correlated with injury $[14,16,17]$. Specifically, decreased hip ER ROM throughout the course of a competitive season has been associated with a history of shoulder pain [16] and elbow pain [18]. Similarly, decreased hip internal rotation (IR) ROM has been associated with an increased risk of lower extremity injury, such as ACL tear [19-21] and groin pain [13]. These findings are troublesome as research has noted players tend to decrease in hip ROM over the course of a ball season [10,22].

Although research has yet to examine ROM alongside BMI within softball pitchers, some reports have acknowledged there to be decreased ROM among retired elite athletes who were of a higher BMI classification [23]. Although decreased ROM is a common adaptation within softball players, it is possible that athletes with a higher BMI may further intensify these ROM adaptations, thus increasing injury susceptibility. Injury rates are already a concern among softball pitchers, as research has shown pitchers are 2.6 times more likely to be injured than positional players. Of similar concern, reports have also revealed pitchers displayed the highest body fat percentage on a collegiate softball team [24] and were the only players on NCAA Division I collegiate teams to increase body fat throughout the course of a season [25]. This highlights the need for research to determine the effects of increased BMI within pitchers, who undergo large physical demands in their pertinent role on the field, and who are regularly exposed to high pitch counts and injury [26].

With research reports suggesting that both decreased ROM and increased BMI are associated with an increased risk of injury, it can be theorized that an increased BMI may be exaggerating ROM deficits leading to an increased risk of injury [24]. Although there have been proposed mechanisms of injury related to higher BMI in athletes, the purpose of the current study was to examine if functional characteristics of hip and shoulder ROM were related to BMI classification. It was hypothesized that a higher classification of BMI would be related to decreased hip and shoulder ROM. Study findings can provide information regarding player body composition and its effect on functional characteristics. In determining how BMI may affect joint ROM, evidence may come to light that links increased BMI with sports injury among softball players and can inform athletes, coaches, athletic trainers, and strength and conditioning personnel on how to help decrease the risk of injury by emphasizing conditioning to promote healthy weight and BMI classification.

\section{Methods}

This was a cross-sectional study designed to examine the influence of BMI on softball pitchers' hip and shoulder ROM. All subjects volunteered to participate and reported to the laboratory for a onetime visit. Subjects' hip and shoulder IR and ER passive ROM were examined after both height and weight were measured. BMI was calculated by dividing weight (in kilograms) by height (in meters) squared $\left(\mathrm{kg} / \mathrm{m}^{2}\right)$.

A convenient sample of 147 female softball pitchers (17.0 \pm 4.2 years; $\left.167.6 \pm 11.8 \mathrm{~cm} ; 70.6 \pm 17.5 \mathrm{~kg} ; \mathrm{BMl}=24.8 \pm 4.7 \mathrm{~kg} / \mathrm{m}^{2}\right)$ were included in the study ( $\triangleright$ Table 1). Body mass index was categorized based on normative values presented by the National Centers for Disease Control and Prevention. The standard weight status categories associated with BMI ranges include underweight (below $18.5 \mathrm{~kg} / \mathrm{m}^{2}$ ), normal (between 18.5 and $24.9 \mathrm{~kg} / \mathrm{m}^{2}$ ), overweight (between 25 and $29.9 \mathrm{~kg} / \mathrm{m}^{2}$ ), and obese (over $30 \mathrm{~kg} / \mathrm{m}^{2}$ ) [27].

All participants were softball pitchers and currently active on a team roster. Prior to data collection, participants were asked to fill out a health history form indicating that they were in good physical condition and had not sustained an injury or undergone surgery in the past 6 months. The University Institutional Review Board approved all testing protocols. Informed written consent and assent were obtained from each subject and their parent/guardian prior to any testing [28]. All testing took place in a controlled laboratory setting. Following the health history questionnaire, participants' bilateral IR and ER passive hip and shoulder ROM were assessed through the use of a handheld inclinometer (Fabrication Enterprises, Inc., White Plains, NY).

Shoulder/glenohumeral IR and ER passive ROM measurements were performed bilaterally with the participant lying supine on an athletic training table. The shoulder was in a position of $90^{\circ}$ of abduction and the elbow was in a position of $90^{\circ}$ flexion. In addition, a rolled towel was placed under the distal humerus to maintain the scapular plane [29-32]. Measurements were performed using standard passive ROM techniques as well as through the visual inspection method to isolate glenohumeral movement and control

- Table 1 Descriptive data per BMI category (mean \pm standard deviation).

\begin{tabular}{|l|c|c|c|c|c|}
\hline & Total & Underweight & Normal & Overweight & Obese \\
\hline $\mathrm{N}$ & 147 & 11 & 66 & 52 & 18 \\
\hline Age (years) & $17.0 \pm 4.2$ & $11.6 \pm 1.6$ & $16.3 \pm 4.3$ & $18.3 \pm 3.6$ & $19.0 \pm 3.5$ \\
\hline Height $(\mathrm{cm})$ & $167.6 \pm 11.8$ & $153.5 \pm 9.2$ & $167.4 \pm 12.8$ & $170.9 \pm 9.2$ & $167.5 \pm 10.5$ \\
\hline Weight $(\mathrm{kg})$ & $70.6 \pm 17.5$ & $40.5 \pm 7.3$ & $62.2 \pm 11.7$ & $79.8 \pm 9.8$ & $93.2 \pm 11.7$ \\
\hline BMI $\left(\mathrm{kg} / \mathrm{m}^{2}\right)$ & $24.8 \pm 4.7$ & $17.0 \pm 1.4$ & $22.0 \pm 1.8$ & $27.2 \pm 1.5$ & $33.2 \pm 2.9$ \\
\hline
\end{tabular}


for scapulothoracic movement [29-32]. The inclinometer was placed on the posterior forearm just above the styloid process of the ulna for IR, and on the anterior surface of the forearm for ER. The examiner placed one hand under the scapula to detect movement and used the other hand to rotate the humerus while holding the inclinometer to the forearm. Maximal IR was recorded when the scapula began to move superiorly and maximal ER was recorded at firm capsular end-feel [29-32].

Hip rotational passive ROM was performed with the participant sitting on an athletic training table with a rolled towel placed under the distal femur and knees flexed at $90^{\circ}[12,31,33]$. The inclinometer was placed on the shaft of the tibia just proximal to the medial malleolus for ER and the shaft of the fibula just proximal to the lateral malleolus for IR. The examiner passively rotated the hip in both IR and ER and reported ROM values when firm capsular endfeel was met $[12,31,33]$.

Intra-rater reliability was assessed using a pilot sample of 7 collegiate softball athletes. Intra-rater reliability was reported using the ROM technique described above, with an $\mathrm{ICC}_{(3, \mathrm{k})}$ of $0.92-0.95$ for all measurements. Clinical significance was calculated via minimal detectable change (MDC) values for the $95 \%$ confidence interval. Glenohumeral joint IR and ER MDCs were $6.8^{\circ}$ and $9.7^{\circ}$, respectively. Hip IR and ER MDC were $5.6^{\circ}$ and $4.7^{\circ}$, respectively.

A one-way multivariate analysis of variance (MANOVA) was conducted to determine the influence of BMI on hip and shoulder ROM. Initially age was predicted to covary with ROM; however preliminary correlations revealed no statistical significance, therefore a one-way MANOVA was used. The independent variable was BMI with four different categories: 1) underweight, 2) normal, 3) overweight, and 4) obese. The dependent variables (DV) included hip and shoulder ROM values to total eight variables. Included at the hip were: throwing side hip IR ROM, throwing side hip ER ROM, glove side hip IR ROM, and glove side ER ROM hip. Included at the shoulder were: dominant shoulder IR ROM, dominant shoulder ER ROM, non-dominant shoulder IR ROM, and non-dominant shoulder ER ROM. The dominant shoulder was defined as the arm the pitcher used to throw the ball, and the non-dominant shoulder referred to the arm that would wear the glove during pitching. The throwing side hip was defined as the hip on the side ipsilateral to the throwing hand, and the glove side hip was defined as the hip on the side ipsilateral to the glove hand/non-dominant shoulder.

\section{Results}

Data were first assessed for outliers through use of the chi-squared $\left(X^{2}\right)$ statistic, the Mahalanobis distance, with a critical value of $p<0.001$. Participants who exceeded the critical value $(n=3)$ were removed from the analysis (total included in the analysis, $n=147$ ) because their ROM values were deemed to differ from the others. Normality and linearity were assessed by bivariate scatterplot matrices. All bivariate relationships revealed an elliptical pattern determining data were normal and had linear interdependent relationships. Multivariate homoscedasticity were observed through the use of Box's M test of equality of covariance matrices [F(108, $4537)=0.997, p=0.491]$, therefore Wilks' $\wedge$ was used to assess multivariate results. MANOVA results indicated BMI [Wilks' $\Lambda=0.742$, $\left.F=1.722, p=0.014, \eta^{2}=0.095\right]$ significantly affected the combined dependent variable (DV) of ROM of the shoulder and hip; however, it is important to note that effect sizes were small. Prior to univariate analysis of variance (ANOVA), the alpha level was corrected to $\alpha=0.00625$ through use of a Bonferroni adjustment to account for all eight DVs [34]. Univariate ANOVA results indicate that throwing side hip IR ROM $\left[F(3,143)=4.341, p=0.006, \eta^{2}=0.083\right]$, glove side hip IR ROM $\left[F(3,143)=4.959, p=0.003, \eta^{2}=0.094\right]$, and dominant shoulder ER ROM $\left[F(3,143)=4.456, p=0.005, \eta^{2}=0.085\right]$ significantly differed between pitcher BMI category. Bonferroni post hoc results indicated the underweight group had significantly more ROM than the obese group in both throwing side hip IR ROM (mean difference $=12.39^{\circ}, p=0.005$ ), and glove side hip IR ROM (mean difference $=11.98^{\circ}, p=0.004$ ). Post hoc tests for the dominant shoulder did not reveal any statistically significant results with the new adjustment of the alpha level. The obese group of pitchers had less shoul-

- Table 2 Means and standard deviations for hip and shoulder ROM values per BMI category.

\begin{tabular}{|c|c|c|c|c|}
\hline \multicolumn{5}{|l|}{ Hip } \\
\hline & \multicolumn{2}{|l|}{ Throwing Side } & \multicolumn{2}{|l|}{ Glove Side } \\
\hline & IR & ER & IR & ER \\
\hline Underweight & $45.58 \pm 12.93^{*}$ & $46.26 \pm 7.93$ & $44.47 \pm 8.55^{*}$ & $47.72 \pm 7.82$ \\
\hline Normal & $38.71 \pm 0.09$ & $42.98 \pm 9.61$ & $38.03 \pm 8.67$ & $44.71 \pm 9.53$ \\
\hline Overweight & $37.45 \pm 10.62$ & $40.67 \pm 7.35$ & $35.43 \pm 8.12$ & $42.58 \pm 7.57$ \\
\hline Obese & $33.19 \pm 9.77^{*}$ & $40.86 \pm 8.75$ & $32.49 \pm 11.38^{*}$ & $41.10 \pm 8.52$ \\
\hline \multicolumn{5}{|l|}{ Shoulder } \\
\hline & \multicolumn{2}{|l|}{ Dominant Side } & \multicolumn{2}{|c|}{ Non-Dominant Side } \\
\hline & IR & ER & $\mathbf{I R}$ & ER \\
\hline Underweight & $45.28 \pm 10.44$ & $108.51 \pm 12.93$ & $45.73 \pm 7.91$ & $101.77 \pm 14.00$ \\
\hline Normal & $47.33 \pm 11.17$ & $105.17 \pm 10.88$ & $49.99 \pm 13.31$ & $105.51 \pm 13.03$ \\
\hline Overweight & $45.30 \pm 7.43$ & $102.18 \pm 12.74$ & $49.12 \pm 9.37$ & $101.66 \pm 10.86$ \\
\hline Obese & $48.23 \pm 8.65$ & $94.66 \pm 13.94$ & $50.53 \pm 9.58$ & $97.38 \pm 10.49$ \\
\hline
\end{tabular}



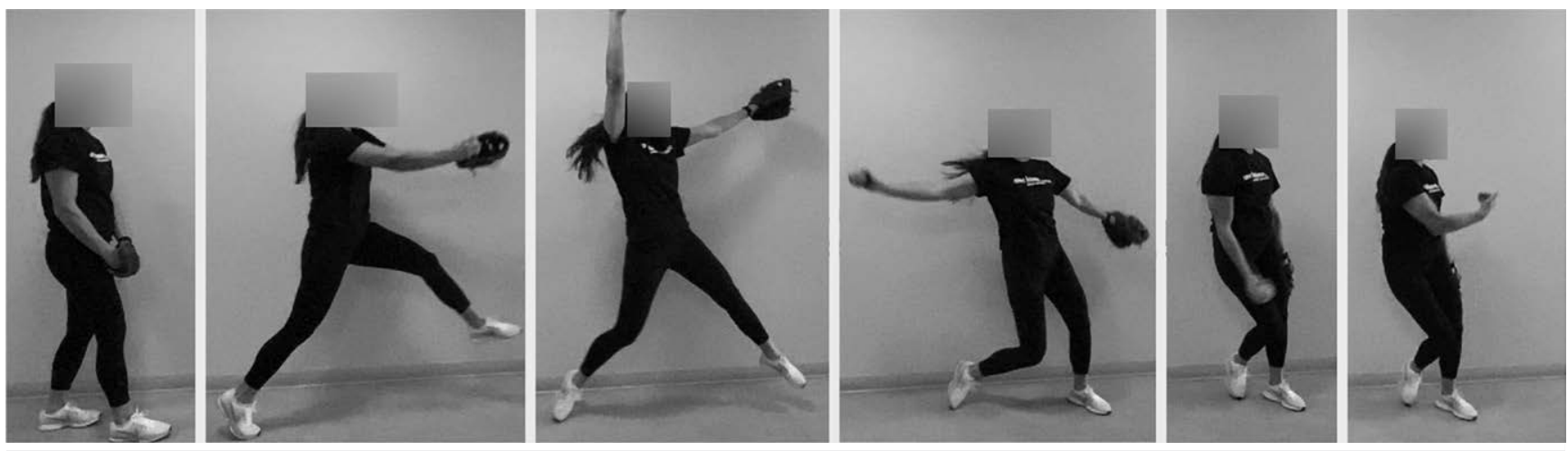

Fig. 1 Events of the windmill softball pitch.

der ER ROM than both the underweight group (mean difference $=13.85, p=0.018$ ), and the normal group (mean difference $=10.36, p=0.009$ ), although these results did not meet the new alpha level criteria. > Table 2 represents means and standard deviations for BMI and hip and shoulder ROM.

\section{Discussion}

The present study aimed to examine the differences in bilateral hip and shoulder ROM between softball pitchers of varying BMI ranges. Our hypothesis was partially supported, with BMI categories revealing differences in hip ROM but not shoulder. Results revealed there were statistically significant differences namely between those who were underweight and those who were obese. These observations were between both throwing side hip IR ROM (mean difference $=12.39^{\circ}$ ) and glove side hip IR ROM (mean difference $=11.98^{\circ}$ ), both of which were statistically and clinically significant.

Hip ROM is vital to the softball pitching motion, as previous research has shown pitchers display higher IR hip ROM than positional players [31]. For discussion purposes, we will break the pitch down into the typical events (start of pitch, top of backswing, foot contact, ball release, follow-through) discussed within the softball literature ( $\triangleright$ Figure $\mathbf{1}$ ). The pitch begins with the pitcher standing with both feet on the plate (throwing side foot touching the front of the plate, and glove side foot touching the back of the plate). As the pitcher drives off the mound, the throwing arm flexes, abducts, and externally rotates to where the upper arm is directly overhead and perpendicular with the ground (commonly referred to as the "top of backswing"). At this point, the trunk has also rotated "open" towards the throwing arm side. Next, the pitcher makes foot contact with the glove side foot while the throwing arm is adducting across the pitcher's body back towards their target. Ball release then happens while the throwing arm is close to the pitcher's throwing side hip, and follow-through terminates the pitch and is usually marked $100 \mathrm{~ms}$ after release of the ball [35]. Typically, the drive portion of the pitch refers to the phase from which the pitcher begins standing neutral and ends at the top of the backswing with the throwing arm perpendicular to the ground. The acceleration phase is known as the phase between the top of the backswing through to ball release.
In a closed kinetic chain, as the throwing side hip initiates a drive off of the mound, the trunk and upper body begin to rotate towards the throwing arm side. If a pitcher does not have adequate IR ROM, she may be inclined to externally rotate her throwing side hip to accommodate the necessary action of the trunk to "open" and gather energy from the more proximal components. Previous reports examining upper extremity pain in softball pitchers have shown that increased trunk rotation towards the throwing arm side has been associated with those who have upper extremity pain [36]. As the throwing side hip externally rotates upon initiation of drive, the body may have a difficult time counteracting this inertia and rotating back to neutral during the acceleration phase of the pitch. This may lead to over-rotation, which as mentioned previously, has been related to injury susceptibility in softball pitchers [36].

Glove-side hip IR was also shown to differ between those who were underweight and those who were obese. Those who were underweight had greater IR ROM of the glove side hip. As the foot of the glove side contacts the ground, the pitcher initiates trunk rotation back towards the catcher. This front leg support acts as a pivot point about which the body segments can accelerate and rotate towards the catcher. As the trunk and upper body rotate back towards the catcher, the glove side hip is undergoing IR. If the pitcher does not have proper IR ROM, she may be landing in a position where the front hip is externally rotated more than usual. Previous reports of kinematics in pitching have shown pitchers tend to orient their front foot approximately 35 degrees towards the throwing side of the body at foot contact [37]. If the pitcher instead lands with more ER, she will theoretically be facing the catcher more, and the transfer of energy throughout the kinetic chain is lost by early initiation of trunk rotation. Vice versa, if the pitcher lands with her front leg internally rotated, as has been shown in the literature, she may have trouble "finishing" the pitch and transferring energy to the front side (towards the batter). Baseball research has noted foot orientation at foot contact angled more towards the throwing arm can decrease pelvis and trunk rotation and ultimately the amount of force transfer from the lower extremity to the upper extremity [38]. Specific to softball, the pitcher's lack of IR ROM of the front hip may inhibit trunk rotation through the latter portion of the pitch and again may alter force generation through the kinetic chain [31]. Future research should measure the stride foot angle in conjunction with measures of hip rotational ROM. 
Although the direct relationships between the decreased ROM and pitching motion are hypothesized, it is well known that altered ROM patterns may lead to injury susceptibility in upper-extremity throwing athletes. Previous reports have shown decreased hip IR ROM to play a role in injury susceptibility in baseball athletes $[13,16,18]$. Although there were no statistically significant differences in ROM values at the shoulder between BMI categories, descriptive data reveal ( $>$ Table 2 ) similar trends at the shoulder. While there is no statistically significant difference between BMI classification groups' shoulder ROM, the authors associate the potential decrease in ROM of the shoulder to be placing the tissues and structures surrounding the glenohumeral joint at increased risk of injury during the highly ballistic and explosive windmill pitch. Overall a lack of statistical significance of shoulder ROM measures was contrary to our hypothesis. With the hips being weight-bearing joints, we can understand why these differences between BMI classification groups are of statistical significance as opposed to the shoulders. In fact, a prior study has suggested adaptations among those with increased body mass are more prominent throughout weightbearing structures [39].

This study has limitations that should be acknowledged. BMI measurement, though widely used, is considered most reliable for adults. The study population age range was between 8 and 27 years; therefore, future studies should examine a more specific cohort of individuals to examine the effects of BMI truer to a specific age range. BMI has also been critiqued as a poor evaluation of athletes, who often present increased muscle mass compared to the general population. Moreover, ROM was measured by the researcher based on end capsular feel and inspection of improper movement. Keep in mind that in extraneous cases, excess body tissue may inhibit true full joint ROM; therefore measurements may be susceptible to error as a result. Lastly, the current study did not measure incidence of pain and injury, therefore future research is warranted to determine the direct association of BMI, ROM, and injury prevalence. This is a preliminary study to display altered ROM in those who have greater BMI. Future research is needed to measure ROM alongside kinematics to portray a clearer picture of how decreased ROM may cause pitchers to be in a more injury prone position during the pitch.

\section{Conclusion}

The current study has implications for softball pitchers, coaches, athletic trainers, and strength and conditioning personnel. Although as body composition is not overly emphasized among softball pitchers, the current study reveals increased BMI may inhibit proper joint ROM, which may influence mechanics and may predispose athletes to an increased risk of injury. Specifically, those with a higher classification of BMI demonstrate less internal rotation of both the glove side and throwing side hip. Future studies should examine true body fat percentage and its effects on pitching biomechanics in hopes of better understanding the effects of excess tissue, not only on general health, but also on performance and injury susceptibility. Coaches, athletic trainers, strength and conditioning personnel, and athletes should acknowledge the role that body composition and fitness can play in affecting pitch performance, injury susceptibility, and athletic career longevity.

\section{Conflict of Interest}

The authors declare that they have no conflict of interest.

\section{References}

[1] Hales CM, Carroll MD, Fryar CD et al. Prevalence of obesity among adults and youth: United States, 2015-2016. NCHS Data Brief 2017; 10: $1-8$

[2] Rose MS, Emery AC, Meeuwusse HW. Sociodemographic predictors of sport injury in adolescents. Med Sci Sports Exerc 2008; 40: 444-450. doi:10.1249/MSS.0b013e31815ce61a

[3] Emery CA. Risk factors for injury in child and adolescent sport: a systematic review of the literature. Clin J Sport Med 2003; 13: 256-268

[4] Richmond SA, Kang J, Emery CA. Is body mass index a risk factor for sport injury in adolescents? J Sci Med Sport 2013; 16: 401-405

[5] Heir T, Eide G. Age, body composition, aerobic fitness and health condition as risk factors for musculoskeletal injuries in conscripts. Scand J Med Sci Sports 1996; 6: 222-227

[6] Kibler WB. Biomechanical analysis of the shoulder during tennis activities. Clin Sports Med 1995; 14: 79-85

[7] Oliver GD, Gilmer GG, Friesen KB et al. Functional differences in softball pitchers with and without upper extremity pain. J Sci Med Sport 2019; 22: 1079-1083

[8] Friesen K, Downs J, Wasserberger $\mathrm{K}$ et al. Glenohumeral and hip range of motion in youth softball athletes. Int J Sports Med. 2019; doi: 10.1055/a-1019-7742

[9] Greenberg E, Lawrence T, Fernandez-Fernandez A et al. Physical and functional differences in youth baseball players with and without throwing-related pain. Orthop J Sports Med 2017; 5: 1-7

[10] Zeppieri G Jr., Lentz TA, Moser MW et al. Changes in hip range of motion and strength in collegiate baseball pitchers over the course of a competitive season: a pilot study. Int J Sports Phys Ther 2015; 10 : 505-513

[11] Picha KJ, Harding JL, Bliven KH. Glenohumeral and hip range-of-motion and strength measures in youth baseball athletes. J Athl Train 2016; 51: 466-473. doi:10.4085/1062-6050-51.7.09

[12] Robb AJ, Fleisig G, Wilk K et al. Passive ranges of motion of the hips and their relationship with pitching biomechanics and ball velocity in professional baseball pitchers. Am J Sports Med 2010; 38: 2487-2493. doi: $10.1177 / 0363546510375535$

[13] Li X, Ma R, Zhou H et al. Evaluation of hip internal and external rotation range of motion as an injury risk factor for hip, abdominal and groin injuries in professional baseball players. Orthop Rev (Pavia) 2015; 7: 6142

[14] Shanley E, Rauh MJ, Michener LA et al. Shoulder range of motion measures as risk factors for shoulder and elbow injuries in high school softball and baseball players. Am J Sports Med 2011; 39: 1997-2006. doi: $10.1177 / 0363546511408876$

[15] Wilk KE, Macrina LC, Fleisig GS et al. Correlation of glenohumeral internal rotation deficit and total rotational motion to shoulder injuries in professional baseball pitchers. Am J Sports Med 2011; 39: 329-335. doi:10.1177/0363546510384223

[16] Scher S, Anderson K, Weber N et al. Associations among hip and shoulder range of motion and shoulder injury in professional baseball players. J Athl Train 2010; 45: 191-197. doi:10.4085/1062-605045.2.191

[17] Shanley E, Michener LA, Ellenbecker TS et al. Shoulder range of motion, pitch count, and injuries among interscholastic female softball pitchers: a descriptive study. Int J Sports Phys Ther 2012; 7: 548-557 
[18] Saito M, Kenmoku T, Kameyama K et al. Relationship between tightness of the hip joint and elbow pain in adolescent baseball players. Orthop J Sports Med 2014; 2: 232596711453242

[19] Bedi A, Warren RF, Wojtys EM et al. Restriction in hip internal rotation is associated with an increased risk of ACL injury. Knee Surg Sports Traumatol Arthrosc 2016; 24: 2024-2031

[20] VandenBerg C, Crawford EA, Enselman ES et al. Restriction in hip rotation is correlated with an increased risk for anterior cruciate ligament injury. Arthroscopy 2017; 33: 317-325

[21] Tainaka K, Takizawa T, Kobayashi H et al. Limited hip rotation and non-contact anterior cruciate ligament injury: A case-control study. Knee 2014; 21: 86-90

[22] Camp CL, Zajac JM, Pearson D et al. The impact of workload on the evolution of hip internal and external rotation in professional baseball players over the course of the season. Orthop J Sports Med 2018; 6: doi: $10.1177 / 2325967117752105$

[23] Kettunen JA, Kujala UM, Räty $\mathrm{H}$ et al. Factors associated with hip joint rotation in former elite athletes. $\mathrm{Br}$ J Sports Med 2000; 34: 44-48

[24] Czeck MA, Raymond-Pope C], Stanforth PR et al. Total and regional body composition of NCAA Division I collegiate female softball athletes. Int J Sports Med 2019; 40: 645-649

[25] Peart A, Wadsworth D, Washington J et al. Body composition assessment in female National Collegiate Athletic Association Division I softball athletes as a function of playing position across a multiyear time frame. J Strength Cond Res 2019; 33: 3049-3055. doi:10.1519/ jsc.0000000000002600

[26] Skillington SA, Brophy RH, Wright RW et al. Effect of pitching consecutive days in youth fast-pitch softball tournaments on objective shoulder strength and subjective shoulder symptoms. Am J Sports Med 2017; 45: 1413-1419

[27] Centers for Disease Control and Prevention Body Mass Index (BMI). 2015; https://www.cdc.gov/healthyweight/assessing/bmi/

[28] Harriss D, MacSween A, Atkinson G. Ethical standards in sport and exercise science research: 2020 update. Int J Sports Med 2020; 40: 813-817
[29] Ellenbecker TS, Roetert EP, Bailie DS et al. Glenohumeral joint total rotation range of motion in elite tennis players and baseball pitchers. Med Sci Sports Exerc 2002; 34: 2052-2056. doi:10.1249/01. MSS.0000039301.69917.0C

[30] Sauers EL, Huxel Bliven KC, Johnson MP et al. Hip and glenohumeral rotational range of motion in healthy professional baseball pitchers and position players. Am J Sports Med 2013; 42: 430-436. doi:10.1177/0363546513508537

[31] Oliver GD, Plummer H, Brambeck A. Hip and glenohumeral passive range of motion in collegiate softball players. Int J Sports Phys Ther 2016; 11: 738-745

[32] Dwelly PM, Tripp BL, Tripp PA et al. Glenohumeral rotational range of motion in collegiate overhead-throwing athletes during an athletic season. J Athl Train 2009; 44: 611-616

[33] Laudner KG, Moore SD, Sipes RC et al. Functional hip characteristics of baseball pitchers and position players. Am J Sports Med 2010; 38: 383-387. doi:10.1177/0363546509347365

[34] Mertler CA, Reinhart RV. Advanced and Multivariate Statistical Methods: Practical Application and Interpretation. 6th ed. New York: Routledge-Taylor \& Francis; 2017

[35] Friesen KB, Barfield JW, Murrah WM et al. The association of upperbody kinematics and earned run average of National Collegiate Athletic Association Division I softball pitchers. J Strength Cond Res. 2019; doi:10.1519/JSC.0000000000003287

[36] Oliver GD, Friesen K, Barfield J et al. Association of upper extremity pain with softball pitching kinematics and kinetics. Ortho J Sports Med 2019; 7: doi:10.1177/2325967119865171

[37] Werner SL, Guido JA, McNeice RP et al. Biomechanics of youth windmill softball pitching. Am J Sports Med 2005; 33: 552-560. doi:10.1177/0363546504269253

[38] Seroyer STNS, Bach BR, Bush-Joseph CA. The kinetic chain in overhand pitching: its potential role for performance enhancement and injury prevention. Sports Health 2010; 2: 135-146

[39] Bollinger LM. Potential contributions of skeletal muscle contractile dysfunction to altered biomechanics in obesity. Gait Posture 2017; 56: 100-107 